\title{
0 cuidado às pessoas idosas em tempos de pandemia
}

\author{
Care for older adults in times of pandemic
}

A emergência da pandemia covid-19 trouxe desafios que têm impactado a assistência direta às pessoas em todos os níveis de atenção à saúde. Entre estes desafios, está a ressignificação do cuidado às pessoas idosas. O desenvolvimento da capacidade para o autocuidado tem emergido como fundamental nestes tempos de pandemia.

No processo de envelhecimento, o autocuidado pode ser caracterizado pelas ações que as pessoas desempenham no seu dia a dia para prevenir, controlar ou reduzir o impacto de condições crônicas sobre sua própria saúde ${ }^{1}$. Já as intervenções da equipe de saúde para auxiliar as pessoas a qualificarem esse processo caracterizam o Autocuidado Apoiado ${ }^{2}$.

A capacidade de entender as ações necessárias para manter a saúde e a capacidade de persistir com o comportamento saudável são aspectos que influenciam no comportamento de saúde. Durante a pandemia, aprendemos que programas que visem à atenção e à promoção da saúde do indivíduo idoso devem oferecer sistemas de apoio ao autocuidado que incluam ações educativas e de reabilitação, para que mesmo a pessoa idosa com algum grau de dependência possa ter a oportunidade de fortalecer a capacidade funcional intrínseca ${ }^{3}$. Os programas que visam à promoção da capacidade intrínseca devem fortalecer o autoconceito, a autoeficácia e o controle desses indivíduos sobre a própria vida. Além disso, tais programas devem promover bons relacionamentos familiares e apoio social.

Para uma vida independente na velhice são necessários recursos materiais e serviços de apoio social. Gabardo-Martins et al. ${ }^{4}$ apontam que uma das dimensões mais importantes do apoio social é o acesso à informação, para que as pessoas sejam capazes de resolver seus problemas de forma autônoma. Por outro lado, é preciso que o indivíduo idoso possua capacidade de dar e receber afeto, de desenvolver empatia e de confiar em outras pessoas. Assim, Gabardo-Martins et al. ${ }^{4}$ também reforçam a importância de relacionamentos capazes de ajudar a pessoa a avaliar a condução de sua própria vida. Quando a pessoa idosa possui acesso ao suporte social com tais qualidades, ela manterá o sentimento de pertencimento e autocuidado, mesmo durante o período de distanciamento social. Neste caso, o distanciamento social não significará isolamento social ${ }^{3}$.

Além dos aspectos relativos ao autocuidado apoiado e ao apoio social, o cuidado à pessoa idosa envolve várias questões que se tornaram mais evidentes com a emergência da pandemia. Para fazer frente a tais desafios, torna-se necessária e urgente a reflexão com base na Ciência, pois ações sem adequado aprofundamento científico resultam em empirismo, muitas vezes, irracional. 
Neste número temático da RBGG espera-se contribuir para o cuidado às pessoas idosas em tempos de pandemia. A intenção é discutir e propor soluções que minimizem os impactos da pandemia na qualidade de vida e saúde da população idosa, com base no conhecimento científico.

Neste sentido, no escopo deste número temático incentivam-se artigos que abordem:

- As demandas do cuidado às pessoas idosas em diferentes contextos (Instituições de Longa PermanênciaILPI; Domiciliar; Hospitalar; Atenção Primária à Saúde) em tempos de pandemia;

- A organização da rede de serviço à saúde para essas novas demandas;

- Possibilidades de respostas ao desafio de atender a essas demandas;

- A saúde mental da pessoa idosa em um contexto de distanciamento social;

- O impacto das desigualdades sociais no cuidado a pessoa idosa em tempos de pandemia;

- A capacitação de cuidadores e familiares de pessoas idosas para essa nova realidade.

\section{Celia Pereira Caldas'}

\section{REFERÊNCIAS}

1. Caldas CP, Lindolpho MC. Promoção do autocuidado na velhice. In: Freitas EV, Py L. Tratado de geriatria e gerontologia. 4 ed. Rio de Janeiro: Guanabara Koogan; 2017. p. 2844-56.

2. Cavalcanti AM, organizador. Autocuidado apoiado: caderno de exercícios. Curitiba: Secretaria Municipal da Saúde; 2012. p. 21

3. Caldas CP, Silva BMC. Ressignificação do cuidado de enfermagem ao idoso no mundo pós-pandemia Covid-19. In: Santana RF, Org. Enfermagem gerontológica no cuidado do idoso em tempos da COVID 19 [Internet]. Brasília, DF: ABen; 2021. p. 151-7. (Série Enfermagem e Pandemias, 5). Disponível em: https://doi.org/10.51234/aben.21.e05.c22

4. Gabardo-Martins LMD, Ferreira MC, Valentini F. Propriedades psicométricas da escala multidimensional de suporte social percebido. Trends Psychol [Internet]. 2017;25(4):1873-83. Disponível em: http://doi.org/doi.org/10.9788/ tp2017.4-18pt 